\title{
Surgery for acquired cardiac disease: An evolving paradigm with a promising future
}

\author{
Bryan A. Whitson, $\mathrm{MD}, \mathrm{PhD},{ }^{\mathrm{a}}$ and Brian Lima, $\mathrm{MD}^{\mathrm{b}}$
}

\footnotetext{
From the a Division of Cardiac Surgery, Department of Surgery, Ohio State University Medical Center, Columbus, Ohio; and the ${ }^{\mathrm{b}}$ Department of Cardiac and Thoracic Surgery, Baylor University Medical Center, Dallas, Tex. Disclosures: Authors have nothing to disclose with regard to commercial support.

Received for publication Aug 11, 2015; revisions received Oct 16, 2015; accepted for publication Jan 5, 2016. Address for reprints: Bryan A. Whitson, MD, PhD, Division of Cardiac Surgery, Department of Surgery, COPPER Laboratory, Ohio State University Medical Center, N-816 Doan Hall, 410 W 10th Ave, Columbus, OH 43210 (E-mail: bryan.whitson@osumc.edu).

J Thorac Cardiovasc Surg 2016;151:1466-9

$0022-5223 / \$ 36.00$

Copyright (c) 2016 by The American Association for Thoracic Surgery

http://dx.doi.org/10.1016/j.jtcvs.2016.01.009
}

The landscape of adult cardiac surgery is evolving at a rapid pace. The proliferation of endovascular techniques, minimally invasive and transcatheter valve therapies, and various device options for mechanical circulatory support has added exponentially to the requisite skill set, knowledge base, and clinical volume for "expertise" in any of these designated niche areas. As such, the days of any single cardiac surgeon capable of adeptly treating all facets of heart failure, structural heart diseases, and coronary artery disease in accordance with modern technologic standards are numbered at best, if not already a historical footnote. The advent and continued expansion of public reporting initiatives by the Society of Thoracic Surgeons ${ }^{1}$ and consumer advocate agencies will subject our field to an unprecedented level of public scrutiny. ${ }^{2}$ Individual surgeon performance, including granular specifics related to outcomes and procedure type, will be cataloged and disseminated to the general public. These widely circulated physician report cards could foreseeably affect remuneration, referral patterns, and scope of practice for individual cardiac surgeons.

Despite these and other challenges that lie on the horizon, the future of surgery for acquired cardiac disease is quite promising, especially from a supply and demand perspective. Specifically, the analysis by Grover and colleagues ${ }^{3}$ pinpointed a number of critical forces that will positively affect our field: (1) projected growth in the aging population with cardiovascular disease, (2) significantly diminished numbers of medical students and general surgical residents seeking cardiac surgical training, and (3) an imminent shortage of cardiac surgeons coupled with an estimated $46 \%$ increased demand by 2025 . Even more encouraging is the fact that these calculations hold true even for the unlikely scenario if coronary artery bypass grafting were to be completely eliminated. The emergence of the collaborative heart team concept for transcatheter aortic valve programs has also fostered enhanced collegiality between cardiac surgeons and referring cardiologists and perhaps has solidified a critical role for cardiac surgeons in the evolution of these therapies going forward. All told, these trends paint a

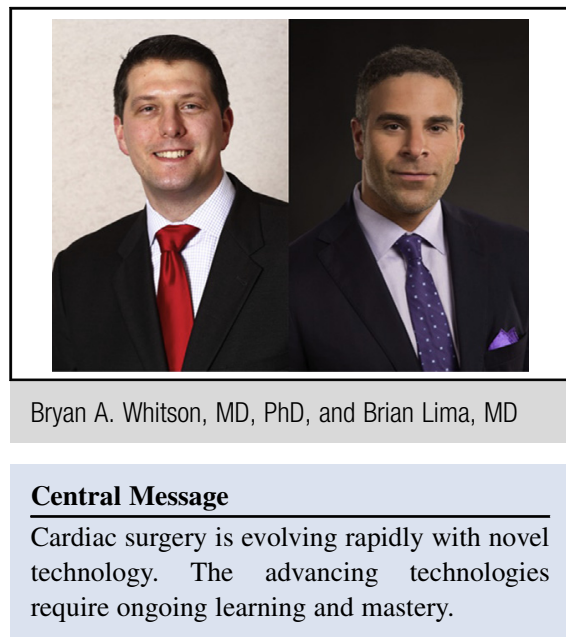

See Editorial Commentary page 1470.

favorable outlook for adult cardiac surgery, including ample employment and career advancement opportunities within the burgeoning niche areas described here.

For the foreseeable future, the onus will be on the individual surgeon to obtain the necessary advanced training to become well versed in one of these superspecialized areas. Such training will probably be above and beyond the scope of a conventional cardiac surgical residency, yet it will be essential to meet the ever-growing expectations of performance and outcomes within each of these specified areas. Simultaneously, however, cardiothoracic surgical resident education must adapt, and proactive steps must be taken to ensure that finishing trainees are sufficiently equipped and specialized to thrive within their respective clinical practices. To accomplish this objective, training programs will invariably require considerable reformation. Ample time for clinical electives to help the surgeon hone specific skill sets must be incorporated into the allotted training period (2-3 year traditional or I-4/I-6 fast-track cardiac programs). To ensure maximum educational benefit, these electives should include options for visiting externships at established centers of excellence, at home or abroad, in the desired field of cardiac surgery. Moreover, for those interested in scholarly pursuits, elective times may include laboratory work or clinical research endeavors. The latter is of utmost relevance, because it will be incumbent on emerging surgeon-investigators to establish the safety, efficacy, and true value of the emerging methodologies highlighted here. 
As our technology and procedures evolve, the unintended consequences of those advances are that there will be a new evolution of cardiothoracic pathology that will need to be addressed. This will require innovation and imagination to treat an ever-aging population with more comorbidities and previously intervened-on conditions. The current procedures may increase or decrease in volume, although there will be a simultaneous increase in the need for newer, innovative approaches.

\section{MECHANICAL CIRCULATORY SUPPORT}

Even as the yearly volume of heart transplantations has remained relatively fixed, the number of durable left ventricular assist device implantations has risen dramatically within the last decade, with approximately a $2500 \%$ increase from 2006 to $2014 .^{4}$ In light of the anticipated, exponential growth in the number of patients with advanced heart failure, including 10 million in the United States alone by 2030 , this trend is expected to continue at an even more accelerated rate. Modern iterations in left ventricular assist device design coupled with refinements in patient selection and perioperative management strategies have also culminated in significant improvements in clinical outcomes, with the 1-year survival now approaching that of cardiac transplantation. ${ }^{5}$ Consequently, the prospect of implementing these therapies in less critically ill patients is being actively investigated, and this will likely become more commonplace in the future as novel and more optimally engineered devices emerge on the market.

Along similar lines, there has been a veritable surge in the number of short-term devices implanted for mechanical circulatory support, including extracorporeal membrane oxygenation and the percutaneous ventricular assist devices such as Impella (ABIOMED, Inc, Danvers, Mass) and TandemHeart (Cardiac Assist, Inc, Pittsburgh, Pa). A recent study that was based on the National Inpatient Sample cites a $1500 \%$ increase in percutaneously implanted devices between 2007 and 2011. ${ }^{6}$ Device options for percutaneous right ventricular support are already being tested and stand to revolutionize the management of patients presenting in hemodynamic extremis with biventricular failure, as well as of patients with left ventricular assist devices who have perioperative right ventricular dysfunction. These and other transformative developments in the field of mechanical circulatory support will invariably lead to much greater demand for highly specialized cardiac surgeons, not only capable of implanting these devices but also well versed in the appropriateness of their use and the nuances of their functional parameters.

\section{MINIMALLY INVASIVE VALVE SURGERY}

As with any other industry, the "customer is always right" mantra is alive and well in the field of cardiac surgery. Patient preference, namely the desire for less- invasive and more cosmetically appealing surgical approaches to treating valvular heart disease, will continue to drive patient referrals toward those surgeons skilled in these methods. Although they are considerably more technically challenging than traditional sternotomy, there is a substantial benefit associated with minimally invasive approaches, including faster recovery, shorter stay, and reduced morbidity. ${ }^{7-9}$ Even in the reoperative setting, or in combined aortic, mitral, and tricuspid valve pathology, the kneejerk reflex to resort to sternotomy will become increasingly second-guessed and frowned upon. Our progressively more tech savvy patient clientele will also be naturally enamored with the concept of robotically assisted surgery, and that skill set will therefore be at a premium.

Concerted efforts to grow transcatheter aortic valve replacement (TAVR) and MitraClip (Abbott Laboratories, Lake Bluff, Ill) programs have culminated in substantial growth of open valve procedure surgical volumes across participating centers. Once again, the expectation by the cardiology constituents of the heart team in these settings will be for minimally invasive valvular approaches in patients deemed at low risk for transcatheter approaches. So certainly the demand will be substantial, but it will be incumbent upon surgeons of the future to adapt willingly and to push the minimally invasive envelope to remain relevant in the field.

\section{TRANSCATHETER VALVE TECHNOLOGY}

The transcatheter approach to valvular pathology has exploded in terms both of clinical interest and need and of the technology being developed to meet those needs. Today we see transcatheter approaches to all 4 valves and many valvular pathologies. These interventions are an ongoing collaboration of cardiothoracic surgeons, interventional cardiologists, and industry. The evolution of these minimally invasive approaches is a natural extension of the decades-long trend toward less-invasive and imageguided therapies. We have witnessed the expansion of percutaneous coronary interventions for coronary revascularization, and we are at the uptick of seeing this revolution in the valvular world as well.

The initial clinical trials in TAVR were conducted by heart teams, a testament that surgeons and cardiologists working together could help usher in novel technology to improve patient care. The initial Placement of Aortic Transcatheter Valve Trial data ${ }^{10}$ demonstrated equivalence in outcome between surgical aortic valve replacement and TAVR at 1 year. As the experience has grown and the technology has matured, the outcomes have improved to the point that in the setting of those patients with an increased surgical risk the TAVR 1-year survival may be superior to that of a surgical approach. ${ }^{11}$ As this technology has evolved from being limited strictly to patients at 
extreme risk ${ }^{12,13}$ to those at intermediate risk, its use has expanded. We are seeing long-term (2- and 5-year) data demonstrating good outcomes, ${ }^{14,15}$ and these technologies are going to continue to expand.

During a rather quick period of adoption (a little more than a decade), the transcatheter and percutaneous valvular technology has matured. With this expansion, we need to expand our armamentarium to address failures of the technology. The ingenuity of our industry and cardiology colleagues is taking our open surgical techniques to the percutaneous arena. MitraClip is one such technology. ${ }^{16}$ This use will continue to expand in creative ways to treat multiple pathologies. ${ }^{17}$ Being able to perform revision surgery or interventions ${ }^{18}$ will be our evolution, in addition to keeping up with the advancing technology. Being able to be creative and develop valve-in-valve strategies ${ }^{19}$ will be mandatory. Similarly, when patients' clinical presentations are not "textbook" or directly fitting the trial approach, innovation in alternative access approaches ${ }^{20,21}$ and hybrid approaches will become more common.

\section{HYBRID CORONARY REVASCULARIZATION}

As mentioned previously, percutaneous coronary intervention has been the archetype for minimally invasive approaches to cardiovascular disease and disruptive technologies. As this approach has matured, we have seen the pendulum swing back and forth, and open-minded individuals are seeing advantages to melding the best of both the surgical and percutaneous coronary intervention worlds. This approach known as hybrid coronary revascularization is expanding and finding its role in the coronary artery disease sphere. ${ }^{22}$ Thoughtful approaches to hybrid revascularization are demonstrating a degree of equipoise to surgical coronary artery revascularization with less morbidity. ${ }^{23}$ These approaches have begun to be used in the treatment of complex pathologies, such as coronary artery disease and valvular disease. ${ }^{24}$

For the hybrid technologies to be used, the cardiothoracic surgeon must be facile with advanced technologies. This mandates at a minimum being able to work in and with a hybrid operating suite. This may be in conjunction with our interventional cardiology colleagues, individually, or both. The surgical robot may have an ideal role in conduit harvesting and potentially anastomoses. The balance of the costs of time and resources to achieve less-invasive revascularization must be addressed at both institutional and national levels. Nevertheless, the next-generation cardiothoracic surgeon will need to be facile with these approaches to some degree.

\section{AORTIC SURGERY}

Among the most striking of the paradigm shifts in adult cardiac surgery has arguably transpired within the realm of aortic surgery. It is in this particular genre of our field that the lines separating cardiac surgeon from vascular surgeon, or interventional radiologist, continue to blur. In years past, patients who survived emergency repair of a Stanford type A dissection would have possibly a single postoperative follow-up visit and get a pat on the back, never to be seen or heard from again. Today, these patients are followed up on a regular basis for surveillance of the remaining thoracic aorta, in much the same way patients with cancer are followed up by their oncologists to monitor for recurrence. The skill set armamentarium of the modern day aortic surgeon is also quite expansive, ranging from the extremes of highly specialized open aortic work (eg, thoracoabdominal aortic aneurysm repairs and valve-sparing aortic root replacements) to thoracic endovascular aortic repair and deployment of branched aortic stent grafts. Very often, cardiac surgeons may work in concert with their vascular surgery colleagues in the management algorithm for patients with aortic disease, including intraoperative surgical assistance. So-called hybrid aortic procedures, such as aortic arch debranching, frozen elephant trunk, and potentially ascending aortic pathology, will continue evolving and garnering extended clinical applicability. ${ }^{25}$ How best to structure training programs efficiently to provide the necessary exposure to both open surgical and catheter-based procedures will be a subject of intense debate. One thing is for certain, however, and that is that for those sufficiently trained a niche in aortic surgery will be very tenable and undoubtedly rewarding.

\section{CONCLUSIONS}

Many a naysayer has said that the field of cardiothoracic surgery is extinct or dying. This is not the case. What the field is clearly doing is evolving. While this evolution is exciting, it does exponentially expand the need for continuing medical education, continuing retooling of skill sets, and innovation. The onus for determining and ensuring safety, efficacy, and value of these approaches is, and should be, on the surgeon. This is our responsibility, and this challenge will provide the opportunity for intellectual, scientific, and academic fulfillment. It is an opportunity for us to continue to distinguish ourselves as leaders in health care.

As C. Walton Lillehei said, "What mankind can dream, research and technology can achieve." 26 The openminded approach to lifelong learning and clinical excellence that cardiothoracic surgeons have will allow us to meet these challenges. As we model excellence in all of these arenas, the training paradigms and need for focused areas of interest will similarly evolve.

\section{References}

1. Shahian DM, Jacobs JP, Edwards FH, Brennan JM, Dokholyan RS, Prager RL, et al. The Society of Thoracic Surgeons national database. Heart. 2013;99: 1494-501. 
2. Dehmer GJ, Drozda JP Jr, Brindis RG, Masoudi FA, Rumsfeld JS, Slattery LE, et al. Public reporting of clinical quality data: an update for cardiovascular specialists. J Am Coll Cardiol. 2014;63:1239-45.

3. Grover A, Gorman K, Dall TM, Jonas R, Lytle B, Shemin R, et al. Shortage of cardiothoracic surgeons is likely by 2020. Circulation. 2009;120:488-94.

4. Lima B, Mack M, Gonzalez-Stawinski GV. Ventricular assist devices: the future is now. Trends Cardiovasc Med. 2015;25:360-9.

5. Kirklin JK, Naftel DC, Pagani FD, Kormos RL, Stevenson LW, Blume ED, et al. Sixth INTERMACS annual report: a 10,000-patient database. J Heart Lung Transplant. 2014;33:555-64.

6. Stretch R, Sauer CM, Yuh DD, Bonde P. National trends in the utilization of short-term mechanical circulatory support: Incidence, outcomes, and cost analysis. J Am Coll Cardiol. 2014;64:1407-15.

7. Bush B, Nifong LW, Chitwood WR Jr. Robotics in cardiac surgery: past, present, and future. Rambam Maimonides Med J. 2013;4:e0017.

8. Glauber M, Ferrarini M, Miceli A. Minimally invasive aortic valve surgery: state of the art and future directions. Ann Cardiothorac Surg. 2015;4:26-32.

9. Lamelas J, Nguyen TC. Minimally invasive valve surgery: when less is more. Semin Thorac Cardiovasc Surg. 2015;27:49-56.

10. Smith CR, Leon MB, Mack MJ, Miller DC, Moses JW, Svensson LG, et al; PARTNER Trial Investigators. Transcatheter versus surgical aortic-valve replacement in high-risk patients. N Engl J Med. 2011;364:2187-98.

11. Adams DH, Popma JJ, Reardon MJ, Yakubov SJ, Coselli JS, Deeb GM, et al; U.S. CoreValve Clinical Investigators. Transcatheter aortic-valve replacement with a self-expanding prosthesis. N Engl J Med. 2014;370:1790-8.

12. Osnabrugge RL, Arnold SV, Reynolds MR, Magnuson EA, Wang K, Gaudiani VA, et al; CoreValve U.S. Trial Investigators. Health status after transcatheter aortic valve replacement in patients at extreme surgical risk: results from the CoreValve U.S. trial. JACC Cardiovasc Interv. 2015;8:315-23.

13. Makkar RR, Fontana GP, Jilaihawi H, Kapadia S, Pichard AD, Douglas PS, et al; PARTNER Trial Investigators. Transcatheter aortic-valve replacement for inoperable severe aortic stenosis. N Engl J Med. 2012;366:1696-704. Erratum in: N Engl J Med. 2012;367:881.

14. Barbanti M, Petronio AS, Ettori F, Latib A, Bedogni F, De Marco F, et al. 5-year outcomes after transcatheter aortic valve implantation with CoreValve prosthesis. JACC Cardiovasc Interv. 2015;8:670-7.
15. Reardon MJ, Adams DH, Kleiman NS, Yakubov SJ, Coselli JS, Deeb GM, et al 2-year outcomes in patients undergoing surgical or self-expanding transcatheter aortic valve replacement. J Am Coll Cardiol. 2015;66:113-21.

16. Feldman T, Kar S, Rinaldi M, Fail P, Hermiller J, Smalling R, et al; EVEREST Investigators. Percutaneous mitral repair with the MitraClip system: safety and midterm durability in the initial EVEREST (Endovascular Valve Edge-to-Edge REpair Study) cohort. J Am Coll Cardiol. 2009;54:686-94.

17. Maisano F, Alfieri O, Banai S, Buchbinder M, Colombo A, Falk V, et al. The future of transcatheter mitral valve interventions: competitive or complementary role of repair vs. replacement? Eur Heart J. 2015;36:1651-9.

18. Argenziano M, Skipper E, Heimansohn D, Letsou GV, Woo YJ, Kron I, et al EVEREST Investigators. Surgical revision after percutaneous mitral repair with the MitraClip device. Ann Thorac Surg. 2010;89:72-80; discussion 80.

19. Keeling B, Chen EP. Double transcatheter valve-in-valve therapy: a viable alternative for high-risk patients. J Thorac Cardiovasc Surg. 2015;150:e17-8.

20. Reardon MJ, Adams DH, Coselli JS, Deeb GM, Kleiman NS, Chetcuti S, et al; CoreValve US Clinical Investigators. Self-expanding transcatheter aortic valve replacement using alternative access sites in symptomatic patients with severe aortic stenosis deemed extreme risk of surgery. J Thorac Cardiovasc Surg. 2014;148:2869-76. e1-7.

21. Thourani VH, Li C, Devireddy C, Jensen HA, Kilgo P, Leshnower BG, et al High-risk patients with inoperative aortic stenosis: use of transapical, transaortic, and transcarotid techniques. Ann Thorac Surg. 2015;99:817-23; discussion 823-5.

22. Gasior M, Zembala MO, Tajstra M, Filipiak K, Gierlotka M, Hrapkowicz T, et al POL-MIDES (HYBRID) Study Investigators. Hybrid revascularization for multivessel coronary artery disease. JACC Cardiovasc Interv. 2014;7:1277-83.

23. Harskamp RE, Vassiliades TA, Mehta RH, de Winter RJ, Lopes RD, Xian Y, et al. Comparative effectiveness of hybrid coronary revascularization vs coronary artery bypass grafting. J Am Coll Surg. 2015;221:326-34.e1.

24. George I, Nazif TM, Kalesan B, Kriegel J, Yerebakan H, Kirtane A, et al Feasibility and early safety of single-stage hybrid coronary intervention and valvular cardiac surgery. Ann Thorac Surg. 2015;99:2032-7.

25. Czerny M, Bachet J, Bavaria J, Bonser RS, Borger MA, De Paulis R, et al The future of aortic surgery in Europe. Eur J Cardiothorac Surg. 2013;43:226-30.

26. Shumway N. Clarence Walton Lillehei. BMJ. 1999;319:856. 